\title{
Clinical Evaluation of Anesthetic Combinations of Xylazine-Ketamine, Diazepam-Ketamine and Acepromazine-Ketamine in Dogs of Local Breed in Mekelle, Ethiopia
}

\author{
Gebremedhin Yohannes ${ }^{1^{*}}$, Guesh negash ${ }^{2}$ and Hagazi Fantay ${ }^{2}$ \\ ${ }^{1}$ College of veterinary medicine, Hawassa University, PO Box 5, Hawassa, Ethiopia \\ ${ }^{2}$ College of veterinary medicine, Mekelle University, PO Box 231, Mekelle, Ethiopia
}

\begin{abstract}
Received: 12 April, 2018; Accepted: 13 May, 2018; Published: 21 May, 2018
*Corresponding author: Gebremedhin Yohannes, College of veterinary medicine, Hawassa University, PO Box 5, Hawassa, Ethiopia, Tel: +251914800882, E-mail: gebyo2005@gmail.com
\end{abstract}

\begin{abstract}
An experimental study was conducted to evaluate the effects of general anesthetic combinations of various drugs i.e. xylazine - ketamine, diazepam - ketamine and acepromazine - ketamine combinations on anesthetic parameters; on physiological and hematological parameters so as to choose a suitable general anesthetic combination for use in surgical procedures in local breed of dogs in Mekelle, Ethiopia. The experimental study was carried out on fifteen local breed of dogs and were randomly divided in to three experimental groups with five dogs in each group. Data was collected for analyzing physiological effects of anesthetic combinations; anesthetic effects and hematological effects using physical recording and laboratory analysis. The results of this study showed duration of general anesthesia was ( $91 \pm 6.28 \mathrm{~min})$ and animal recovered (101.2 $\pm 6.5 \mathrm{~min})$ and was longer in xylazine-ketamine combination, whereas duration of general anesthesia was (44.8 $\pm 1.92 \mathrm{~min})$ and animal recovered (55.6 \pm 3.85 $\mathrm{min}$ ) and was shorter in diazepam -ketamine combination. The result also showed that the physiological and hematological parameters remained significantly unchanged during the anesthesia in all groups. Therefore, relation duration of action, xylazine and ketamine combination was a suitable choice for undertaking of surgical operations in dogs of local breed for longer duration of action i.e. $(91 \pm 6.28 \mathrm{~min})$ whereas diazepam and ketamine combination was a suitable choice for shorter duration of action i.e. (44.8 $\pm 1.92 \mathrm{~min})$. Further studies on several other anesthetic combinations i.e. (acepromazine + xylazine + ketamine and acepromazine + diazepam + ketamine) on local breed of dogs and several other anesthetic combinations may be conducted.
\end{abstract}

Key words: Diazepam; Ethiopia; General anesthesia; ketamine; Local breed of dogs; Mekelle

Abbreviations: AK-Acepromazine -Ketamine; ANOVA-Analysis of Variance; CSA-Central Statistical Agency; DK-Diazepam - Ketamine; DLDifferential Leukocyte Counts; EDTA-Ethylene Diamine Tetra acetic acid; GABAA-.Gamma-Amino Butyric Acid type A receptors; HbC-Hemoglobin Concentration; IM-Intramuscular; Kg-Kilo gram; mg-milligram; PCV-Packed Cell Volume; SD-Standard Deviation; SPSS-Statistical Package for Social Sciences; TEC-Total Erythrocyte count; TLC-Total Leukocyte count; XK-Xylazine - Ketamine

\section{Introduction}

Ketamine is combined with an alpha-2-agonist (e.g. xylazine), a benzodiazepine (e.g. diazepam) or a phenothiazine tranquillizer (e.g. acepromazine) to enhance muscle relaxation, analgesia, to prevent seizures/convulsions and prolong the duration of anesthetic effect. It is associated with a rapid onset, good to excellent sedation of one to two hours duration, excellent analgesia and smooth recovery. The analgesia and sedation are due to central nervous system depression and the muscle relaxation is due to the central inhibition of intraneural transmission [22].

The combination of ketamine hydrochloride and xylazine $\mathrm{HCl}$ usually result in a smooth induction and recovery with cataleptic effects of ketamine $\mathrm{HCl}$ get ameliorated by the sedative and my relaxing effects of xylazine $\mathrm{HCl}[10,15]$.
Diazepam is associated with occasional individual variability in response. Moreover, its solvent (propylene glycol) may produce hypotension. Acepromazine has prolonged duration of sedation effect and is associated with hypotension secondary to marked peripheral vasodilatation. The combination of diazepam and ketamine is commonly described protocol for induction of general anesthesia in healthy dogs of various ages. It may also be indicated in certain cases with cardiovascular compromises $[7,12,16]$. This combination has proved good in providing excitement-free induction of anesthesia in dogs $[6,31]$.

Ketamine is poor in visceral analgesia. However, it can be used in combination with xylazine or diazepam to provide good visceral analgesia in case of abdominal surgery (including ovariohysterectomy) and thoracic surgery. Pain is an unpleasant sensory or emotional experience most commonly associated with potential tissue damage. The sensation of pain is a consequence of 


\section{Diazepam-Ketamine and Acepromazine-Ketamine in Dogs of Local Breed in Mekelle, Ethiopia}

the activation of specialized receptors and neurological pathways after such pain stimuli $[17,21]$.

Studies on acute pain in clinical cases have most often evaluated the effects of surgical trauma on animals, while prevention and pain management are the key issues in anesthesia $[14,22,28]$. When pain is not appropriately managed, it is not only an animal welfare issue, but it can also have many detrimental effects which can impact the patient recovery [26]. A variety of physiological changes also occur in response to pain such as increases in heart rate, respiratory rate, blood pressure and body temperature $[3,5,14]$.

Ketamine is rarely used alone because of its association with poor muscle relaxation, tachycardia and catalepsy or muscle rigidity. Therefore, it is commonly used in combination with xylazine, diazepam and acepromazine to minimize the adverse effects. Moreover, there are different breed of dogs which require proper anesthetic medicament combination. However, there are limited or no experiments carried out to determine a specific anesthetic combination in relation to the local breed of dogs in the study area. Hence, determining the effects of the ketamine in combination with other sedative agents may help to come out with the safest combination for surgical procedures in local breed of dogs. Therefore, the purpose of this study is to evaluate the effects of xylazine-ketamine, diazepam-ketamine and acepromazine-ketamine on anesthetic, physiological and hematological parameters so as to choose a suitable general anesthetic combination for use in surgical procedures in local breed of dogs in Mekelle, Ethiopia.

\section{Materials and Methods}

\section{Study Area}

The present study was conducted from November 2016 to April 2017 in Mekelle, Tigray, Ethiopia. Mekelle is the capital of Tigray region located about 783 kilometers north of Addis Ababa with a total area of approximately 102,000 square kilo meters. Its geographic location is $13032^{`} \mathrm{~N}$ latitude and $39033^{`} \mathrm{E}$ longitude with human population of about 215,546 . It has an average altitude of 2200 meter above sea level with a mean minimum and maximum monthly temperature of 8.7 degree Celsius and 26.8 degree Celsius respectively. The annual average rainfall of Mekelle is 600 millimeters and more than 70 percent of it falls between the months July and August. The long dry season extends from October to May [8].

\section{Study Population}

The present study was carried out on mature and apparently healthy local breed of dogs weighing between 10-15 kg and aged between 2-4 years. Dogs were declared healthy based on physiologically normal parameters i.e. rectal temperature, heart rate, respiratory rate, and capillary refill time.

\section{Sample Size}

The present study was carried out on fifteen mature and apparently healthy local breed of dogs (twelve males and three females).

\section{Sampling Technique}

Fifteen dogs were randomly divided in to three experimental groups with five dogs (four males and one female) in each group.

\section{Experimental Design and Procedure}

Fifteen (15) local breed of dogs were purchased, of which five dogs were randomly assigned to an induction regimen of xylazine-ketamine (Group 1), the other five dogs were assigned to diazepam-ketamine (Group 2) and the rest five dogs were assigned to acepromazine-ketamine (Group 3).

The dogs were housed individually in a kennel, fed meat and bread. Prior to anesthesia, each dog was withheld of food and water for 12 and 6 hours respectively. These dogs were placed in a quiet kennel and left undisturbed. Heart rate, respiratory rate and temperature were recorded prior to premedication. Blood samples were taken prior to premedication. All dogs were premedicated with atropine sulphate at $0.04 \mathrm{mg} / \mathrm{kg}$ body weight subcutaneously for the reduction of salivary and bronchial secretions fifteen minutes before induction of anesthesia with xylazine - ketamine, diazepam - ketamine and acepromazine ketamine.

\section{Administration of Drugs}

Group 1: First all dogs were premedicated with atropine sulphate at $0.04 \mathrm{mg} / \mathrm{kg}$ body weight subcutaneously. After fifteen minutes of premedication, a combination of xylazine and ketamine were administered at two different doses xylazine and ketamine at $1 \mathrm{mg} / \mathrm{kg}$ and $2 \mathrm{mg} / \mathrm{kg}$ respectively and again xylazine and ketamine at $2 \mathrm{mg} / \mathrm{kg}$ and $10 \mathrm{mg} / \mathrm{kg}$ IM respectively with one week interval between trials.

Group 2: First all dogs were premedicated with atropine sulphate at $0.04 \mathrm{mg} / \mathrm{kg}$ body weight subcutaneously. After fifteen minutes of premedication, a combination of diazepam and ketamine at two different doses diazepam and ketamine at $0.1 \mathrm{mg} / \mathrm{kg}$ and $5 \mathrm{mg} / \mathrm{kg}$ respectively and again at $0.5 \mathrm{mg} / \mathrm{kg}$ and $10 \mathrm{mg} / \mathrm{kg}$ intramuscularly respectively with one week interval between trials.

Group 3: First all dogs were premedicated with atropine sulphate at $0.04 \mathrm{mg} / \mathrm{kg}$ body weight subcutaneously. After fifteen minutes of premedication, a combination of acepromazine and ketamine at two different doses acepromazine and ketamine at $0.01 \mathrm{mg} / \mathrm{kg}$ and $5 \mathrm{mg} / \mathrm{kg}$ respectively and again acepromazine and ketamine at $0.05 \mathrm{mg} / \mathrm{kg}$ and $10 \mathrm{mg} / \mathrm{kg}$ intramuscularly respectively with one week interval between trials.

\section{Monitoring of Post Intervention}

After administration of the xylazine-ketamine, diazepamketamine and acepromazine -ketamine, dogs of all groups were kept under close observation. Induction period, duration of anesthesia and recovery period were recorded. Rectal temperature, respiratory rate, and heart rate were recorded every 5 minutes interval after administration of the anesthetic combinations. 


\section{Hematological and Physiological Parameters}

Three ml of blood sample were collected from cephalic vein of each experimental dog prior to administration of the premedication (atropine sulphate) and 30-45 minutes after administration of the xylazine - ketamine, diazepam - ketamine and acepromazine -ketamine; because maximum effects of the xylazine-ketamine, diazepam-ketamine and acepromazineketamine occurred at 30-45 minutes. Immediately after collection, the blood samples were transferred in a sterile test tube containing Ethylene Diamine Tetra acetic acid (EDTA) as anticoagulant for estimation of Packed Cell Volume, White blood cells, Hemoglobin concentration, red blood cells and differential leukocyte counts according to the procedures of [25]. Physiological parameters like heart rate, respiratory rate and rectal temperature were measured every five minutes after administration of the anesthetic combinations.

\section{Data Collection}

Data were collected on physiological effects (heart rate, respiratory rate and rectal temperature), anesthetic effects (induction period, duration of anesthesia, recovery period,) and hematological effects (packed cell volume, red blood cells, white blood cells, hemoglobin concentration and differential leukocyte counts.

\section{Data Analysis}

The recorded data was entered into Microsoft excel sheet and analyzed to Mean \pm SD (Standard Deviation) using Statistical Package for Social Sciences (SPSS) version 17.0 [32]. Paired t-test was used to compare physiological and hematological parameters taken before and during the administration of the drug combination for each group. One-Way Analysis of Variance (ANOVA) at 95\% confidence interval (CI) was used to determine the level of significant difference in mean values among three groups; to compare the means of induction time, duration of anesthesia and recovery time between the groups. Values of $\mathrm{p} \leq 0.05$ were considered as statistical significant and Values of p $>0.05$ was considered as non-significant.

\section{Results}

\section{Anesthetic Effects Ketamine-Anesthetic Combinations}

In this study, the recorded onset of action, duration of action and recovery time of the anesthetic combination of xylazine - ketamine at a respective dose of $1 \mathrm{mg} / \mathrm{kg}$ and $5 \mathrm{mg} / \mathrm{kg}$ body weight given intramuscularly were $8 \pm 2.12$ minutes, $68 \pm 6.28$ minutes and $78.2 \pm 6.53$ minutes, respectively. The recorded onset of action, duration of action and recovery time of the anesthetic combination of xylazine - ketamine at a respective dose of $2 \mathrm{mg} /$ $\mathrm{kg}$ and $10 \mathrm{mg} / \mathrm{kg}$ body weight given intramuscularly were $6 \pm$ $2.12,91 \pm 6.28$ and $101.2 \pm 6.53$ minutes, respectively. In this study, onset of action was shorter whereas duration of action and recovery time were longer in the anesthetic combination of xylazine - ketamine at a respective dose of $2 \mathrm{mg} / \mathrm{kg}$ and 10 $\mathrm{mg} / \mathrm{kg}$ body weight given intramuscularly when compared to the anesthetic combination of xylazine - ketamine at a respective dose of $1 \mathrm{mg} / \mathrm{kg}$ and $5 \mathrm{mg} / \mathrm{kg}$ body weight given IM (Table 1).

The recorded onset of action, duration of action and recovery time of the anesthetic combination of diazepam - ketamine at 0.1 $\mathrm{mg} / \mathrm{kg}$ and $5 \mathrm{mg} / \mathrm{kg}$ body weight given intramuscular, respectively were $12 \pm 2.12,37.8 \pm 1.92$ and $47.8 \pm 1.92$ minutes, respectively. The recorded onset of action, duration of action and recovery time of the anesthetic combination of diazepam - ketamine at $0.5 \mathrm{mg} / \mathrm{kg}$ and $10 \mathrm{mg} / \mathrm{kg}$ body weight given IM, respectively were $10 \pm 2.12,44.8 \pm 1.92$ and $55.6 \pm 3.85$ minutes, respectively. In this study, onset of action was shorter whereas duration of action and recovery time were longer in the anesthetic combination of diazepam - ketamine at $0.5 \mathrm{mg} / \mathrm{kg}$ and $10 \mathrm{mg} / \mathrm{kg}$, respectively when compared to the anesthetic combination of diazepam ketamine at $0.1 \mathrm{mg} / \mathrm{kg}$ and $5 \mathrm{mg} / \mathrm{kg}$, IM (Table 1).

Table 1: Effects of xylazine-ketamine, diazepam-ketamine and acepromazine-ketamine combinations on onset of action, duration and recovery time

\begin{tabular}{|c|c|c|c|}
\hline Anesthetic combinations & Doses $(\mathrm{mg} / \mathrm{kg})$ & Onset of action (min) & Duration of action (min) \\
\hline Group 1 & $1 \mathrm{mg} / \mathrm{kg}$ and $5 \mathrm{mg} / \mathrm{kg}$ & $8 \pm 2.12$ & $68 \pm 6.28$ \\
\hline & $2 \mathrm{mg} / \mathrm{kg}$ and $10 \mathrm{mg} / \mathrm{kg}$ & $6 \pm 2.12$ & $91 \pm 6.28$ \\
\hline Group 2 & $0.1 \mathrm{mg} / \mathrm{kg}$ and $5 \mathrm{mg} / \mathrm{kg}$ & $12 \pm 2.12$ & $37.8 \pm 1.92$ \\
\hline Group 3 & $0.5 \mathrm{mg} / \mathrm{kg}$ and $10 \mathrm{mg} / \mathrm{kg}$ & $10 \pm 2.12$ & $44.8 \pm 1.92$ \\
\hline & $0.01 \mathrm{mg} / \mathrm{kg}$ and $5 \mathrm{mg} / \mathrm{kg}$ & $13 \pm 2.12$ & $62.8 \pm 2.28$ \\
\hline
\end{tabular}

The recorded onset of action, duration of action and recovery time of the anesthetic combination of Acepromazine - ketamine at $0.01 \mathrm{mg} / \mathrm{kg}$ and $5 \mathrm{mg} / \mathrm{kg}$ body weight given intramuscular, respectively were $13 \pm 2.12,62.8 \pm 2.28$ and $72.8 \pm 2.28$ minutes, respectively. The recorded onset of action, duration of action and recovery time of the anesthetic combination of diazepam - ketamine at $0.05 \mathrm{mg} / \mathrm{kg}$ and $10 \mathrm{mg} / \mathrm{kg}$ body weight given $\mathrm{IM}$, respectively were $11 \pm 2.12,78.6 \pm 1.67$ and $88.6 \pm 1.67$ minutes, respectively. In this study, onset of action was shorter whereas duration of action and recovery time were longer in the anesthetic combination of Acepromazine - ketamine at $0.05 \mathrm{mg} /$ $\mathrm{kg}$ and $10 \mathrm{mg} / \mathrm{kg}$, respectively when compared to the anesthetic combination of Acepromazine - ketamine at $0.01 \mathrm{mg} / \mathrm{kg}$ and 5 $\mathrm{mg} / \mathrm{kg}$, respectively. In this study, significant difference in onset of action $(\mathrm{P}=0.04)$, duration of action $(\mathrm{P}=0.015)$ and recovery time $(\mathrm{P}=0.031)$ were observed between the three anesthetic 
groups. Duration of action ( $44.8 \pm 1.92 \mathrm{~min})$ and recovery time (55.6 $\pm 3.85 \mathrm{~min}$ ) were shorter in group 2 (diazepam -ketamine), but longer duration of action ( $91 \pm 6.28 \mathrm{~min})$ and recovery time $(101.2 \pm 6.53 \mathrm{~min})$ were observed in group 1 (xylazine-ketamine) (Table 1).

\section{Body Reflexes Activity}

\section{Rightening Reflex}

In the current study, the different body reflexes activities were assessed during the anesthesia for the sake of assessing the depth of anesthesia. The rightening reflex was elicited by squeezing or pinching a digit of fore limb and observed whether the dog flexes the leg or withdraws the digit from the investigator during the examination after administration of the anesthetic combinations.

In group 1 the rightening reflex was lost at $8 \pm 2.12$ minutes in xylazine-ketamne at dose rate of $1 \mathrm{mg} / \mathrm{kg}$ and $5 \mathrm{mg} / \mathrm{kg}$, respectively, $6 \pm 2.12$ minutes in xylazine-ketamne at $2 \mathrm{mg} / \mathrm{kg}$ and $10 \mathrm{mg} / \mathrm{kg}$, respectively (Table 2). In group 2 this reflex was lost at $12 \pm 2.12$ minutes (Table 2). In group 3 this reflexes was lost at $13 \pm 2.12$ minutes (Table 2). In this study, the rightening reflex remained unchanged throughout the anesthesia in all groups.

\section{Palpebral Reflex}

The palpebral reflex was tested by lightly taping the lateral canthus or medial canthus of the eye and observed whether the dog blinks in response after administration of the anesthetic combinations. In group one the palpebral reflex was lost at 8.1 \pm 2.12 minutes in xylazine-ketamne at $1 \mathrm{mg} / \mathrm{kg}$ and $5 \mathrm{mg} / \mathrm{kg}$, respectively, $6.1 \pm 2.12$ minutes in xylazine-ketamne at $2 \mathrm{mg} / \mathrm{kg}$ and $10 \mathrm{mg} / \mathrm{kg}$, respectively (Table 2 ). In group two this reflex was lost at $12.2 \pm 2.12$ minutes (Table 2). In group three this reflexes was lost at $13.2 \pm 2.12$ minutes (Table 2 ). In this study, the palpebral reflex remained unchanged throughout the anesthesia in all groups.

\section{Corneal Reflex, Eye Position and Pupil Size}

Corneal reflex was tested by touching the cornea with a drop of sterile water and noted whether the dog blinks in response and withdraws the eye into the orbital fossa. In this observation, the time for corneal reflex loss was the same as to the time loss for palpebral reflex in all the three groups. In group 1 the corneal reflex was lost at $8.1 \pm 2.12$ minutes in xylazine-ketamne administered at dose rate of $1 \mathrm{mg} / \mathrm{kg}$ and $5 \mathrm{mg} / \mathrm{kg}$, respectively, $6.1 \pm 2.12$ minutes in xylazine-ketamne at $2 \mathrm{mg} / \mathrm{kg}$ and $10 \mathrm{mg} /$ $\mathrm{kg}$, respectively (Table 2). In group two this reflex was lost at 12.2 \pm 2.12 minutes (Table 2). In group three this reflexes was lost at $13.2 \pm 2.12$ minutes (Table 2).

In all groups the eyes remained opened, with a central and dilated pupil during the anesthesia. In this study, the corneal reflex remained unchanged throughout the anesthesia in all groups.

\section{Pedal Reflex}

The pedal reflex was elicited by squeezing or pinching a digit of hind limb and observed whether the dog flexes the leg or withdraws the digit from the investigator during the examination after administration of the anesthetic combinations. In group 1 the pedal reflex was lost at $8.6 \pm 2.12$ minutes in xylazine-ketamne at $1 \mathrm{mg} / \mathrm{kg}$ and $5 \mathrm{mg} / \mathrm{kg}$, respectively, $6.6 \pm 2.12$ minutes in xylazine-ketamne at $2 \mathrm{mg} / \mathrm{kg}$ and $10 \mathrm{mg} / \mathrm{kg}$, respectively (Table 2). In group 2 this reflex was lost at $12.5 \pm 2.21$ minutes (Table 2). In group 3 this reflexes was lost at $13.7 \pm 2.22$ minutes (Table 2). In this study, the pedal reflex remained unchanged throughout the anesthesia in all groups.

\begin{tabular}{|c|c|c|c|c|c|}
\hline \multicolumn{6}{|c|}{ Loss of body reflexes in minutes } \\
\hline Anesthetic combinations & Doses(mg/kg) & Rightening reflex & Palpebral reflex & Corneal reflex & Pedal reflex \\
\hline \multirow{2}{*}{ Group 1} & $1 \mathrm{mg} / \mathrm{kg}$ and $5 \mathrm{mg} / \mathrm{kg}$ & $8 \pm 2.12$ & $8.1 \pm 2.02$ & $8.1 \pm 2.02$ & $8.6 \pm 2.42$ \\
\hline & $2 \mathrm{mg} / \mathrm{kg}$ and $10 \mathrm{mg} / \mathrm{kg}$ & $6 \pm 2.12$ & $6.1 \pm 2.02$ & $6.1 \pm 2.02$ & $6.6 \pm 2.42$ \\
\hline \multirow{2}{*}{ Group 2} & $0.1 \mathrm{mg} / \mathrm{kg}$ and $5 \mathrm{mg} / \mathrm{kg}$ & $12 \pm 2.12$ & $12.2 \pm 2.12$ & $12.2 \pm 2.12$ & $12.5 \pm 2.23$ \\
\hline & $0.5 \mathrm{mg} / \mathrm{kg}$ and $10 \mathrm{mg} / \mathrm{kg}$ & $10 \pm 2.12$ & $10.2 \pm 2.12$ & $10.2 \pm 2.12$ & $10.5 \pm 2.23$ \\
\hline \multirow{2}{*}{ Group 3} & $0.01 \mathrm{mg} / \mathrm{kg}$ and $5 \mathrm{mg} / \mathrm{kg}$ & $13 \pm 2.12$ & $13.2 \pm 2.12$ & $13.2 \pm 2.12$ & $13.7 \pm 2.22$ \\
\hline & $0.05 \mathrm{mg} / \mathrm{kg}$ and $10 \mathrm{mg} / \mathrm{kg}$ & $11 \pm 2.12$ & $11.2 \pm 2.12$ & $11.2 \pm 2.12$ & $11.7 \pm 2.22$ \\
\hline
\end{tabular}

Effects of Xylazine and Ketamine Combination on Physiological Parameters

Heart rate, respiratory rate and rectal temperature were recorded every 5 minutes after administration of the anesthetic combination of xylazine and ketamine up to the time of recovery. The recorded heart rate, respiratory rate and rectal temperature at 60 minutes after administration of xylazine and ketamine were the same as to the recorded values before administration of the xylazine and ketamine so not analyzed; only those values recorded up to 60 minutes were analyzed. In this study, the heart rate was decreased non- significantly $(\mathrm{P}=0.061)$ from 30 minutes up to 45 minutes after administration of the combination of xylazine - ketamine (Table 3). The recorded respiratory rate was decreased non- significantly $(\mathrm{P}=0.065)$ from 10 minutes up to 45 minutes following administration of the combination of xylazine - ketamine (Table 3). The recorded rectal temperature was also decreased non- significantly $(\mathrm{P}=0.063)$ from 20 minutes up to 45 minutes after administration of the combination of xylazine ketamine on both doses (Table 3). 


\section{Diazepam-Ketamine and Acepromazine-Ketamine in Dogs of Local Breed in Mekelle, Ethiopia}

\begin{tabular}{|c|c|c|c|c|c|c|c|c|c|c|c|c|c|}
\hline \multirow[t]{2}{*}{ Parameters } & \multicolumn{13}{|c|}{ Time interval in minutes } \\
\hline & BA & 5 & 10 & 15 & 20 & 25 & 30 & 35 & 40 & 45 & 50 & 55 & 60 \\
\hline HR (beat/min) & $80.1 \pm 2.2$ & $79.8 \pm 2.23$ & $79.5 \pm 2.24$ & $79.3 \pm 2.34$ & $78.2 \pm 2.26$ & $77.4 \pm 2.28$ & $74.2 \pm 2.34$ & $73.4 \pm 2.35$ & $72.5 \pm 2.41$ & $72.3 \pm 2.47$ & $79.3 \pm 2.35$ & $79.5 \pm 2.24$ & $79.8 \pm 2.23$ \\
\hline $\mathrm{RR}($ breath $/ \mathrm{min}$ ) & $23.7 \pm 0.7$ & $23.1 \pm 0.78$ & $18.6 \pm 0.8$ & $17.4 \pm 0.91$ & $17.4 \pm 0.92$ & $16.6 \pm 1.13$ & $15.7 \pm 1.24$ & $15.4 \pm 1.36$ & $15.0 \pm 1.34$ & $20.2 \pm 0.77$ & $23.2 \pm 0.77$ & $23.2 \pm 0.64$ & $23.5 \pm 0.53$ \\
\hline $\operatorname{RT}(0 \mathrm{c})$ & $37.8 \pm 0.77$ & $37.76 \pm 0.79$ & $37.68 \pm 0.80$ & $37.64 \pm 0.85$ & $37.45 \pm 0.87$ & $37.42 \pm 0.89$ & $37.4 \pm 0.912$ & $37.35 \pm 0.93$ & $37.29 \pm 0.95$ & $37.182 \pm 1.02$ & $37.68 \pm 0.84$ & $37.69 \pm 0.79$ & $37.78 \pm 0.69$ \\
\hline
\end{tabular}

In this study, the heart was decreased non- significantly $(\mathrm{P}=$ 0.064 ) from 30 minutes up to 40 minutes after administration of the anesthetic combination of diazepam - ketamine on both doses (Table 4). The recorded respiratory rate was decreased non- significantly $(P=0.067)$ from 10 minutes up to 40 minutes following administration of the anesthetic combination of diazepam - ketamine on both doses (Table 3). The recorded rectal temperature was also decreased non- significantly $(\mathrm{P}=$ 0.065 ) from 20 minutes up to 40 minutes after administration of the anesthetic combination of diazepam - ketamine on both doses (Table 4).

\section{Effects of Acepromazine and Ketamine Combination on Physiological Parameters}

In this study, the heart was decreased non- significantly ( $\mathrm{P}=$ 0.066) from 30 minutes up to 45 minutes after administration of the anesthetic combination of acepromazine - ketamine on both doses (Table 5, Table 6). The recorded respiratory rate was decreased non- significantly $(\mathrm{P}=0.069)$ from 10 minutes up to 45 minutes following administration of the anesthetic combination of acepromazine - ketamine on both doses (Table 5, Table $6)$. The recorded rectal temperature was also decreased nonsignificantly $(\mathrm{P}=0.067)$ from 20 minutes up to 45 minutes after administration of the anesthetic combination of acepromazine ketamine on both doses (Table 5,Table 6).
In the current study, blood samples were taken before and during administration of the anesthetic combinations of xylazineketamine, diazepam-ketamine and acepromazine-ketamine for evaluating of hemoglobin concentration, packed cell volume, total erythrocyte count, total leukocyte count, neutrophils, lymphocytes, monocytes, eosinophils and basophils.

In group 1 hemoglobin concentration $(P=0.066)$, packed cell volume $(\mathrm{P}=0.073)$, total erythrocyte count $(\mathrm{P}=0.069)$, total leukocyte count $(\mathrm{P}=0.079)$, lymphocyte $(\mathrm{P}=0.064)$, monocyte $(\mathrm{P}=0.061)$, eosinophil $(\mathrm{P}=0.074)$ and basophils $(\mathrm{P}=0.084)$ were decreased non-significantly, Neutrophils $(\mathrm{P}=1.000)$ were increased non-significantly from $58.8 \pm 0.39$ to $64 \pm 0.68$ (Table 6).

In group 2 hemoglobin concentration $(\mathrm{P}=0.062)$, packed cell volume $(\mathrm{P}=0.065)$, total erythrocyte count $(\mathrm{P}=0.067)$, total leukocyte count $(\mathrm{P}=0.078)$, lymphocyte $(\mathrm{P}=0.084)$, monocyte $(\mathrm{P}$ $=0.071)$, eosinophil $(\mathrm{P}=0.0614)$ and basophils $(\mathrm{P}=0.083)$ were decreased non-significantly, on the other hand, neutrophils $(\mathrm{P}=$ 1.0211 ) were increased non-significantly from $58.8 \pm 0.39$ to 66.5 \pm 0.34 (Table 6).

In group 3 hemoglobin concentration $(\mathrm{P}=0.076)$, packed cell volume $(\mathrm{P}=0.073)$, total erythrocyte count $(\mathrm{P}=0.069)$, total leukocyte count $(\mathrm{P}=0.089)$, lymphocyte $(\mathrm{P}=0.0714)$, monocyte $(\mathrm{P}=0.0831)$, eosinophil $(\mathrm{P}=0.0724)$ and basophils $(\mathrm{P}=0.0806)$ were decreased non-significantly, on the other hand, neutrophils $(\mathrm{P}=1.0221)$ were increased non-significantly from $58.8 \pm 0.39$ to $66.58 \pm 0.34$ (Table 6).

Table 4: Effects of diazepam and ketamine combination on heart rate, respiratory rate and rectal temperature of experimental dogs
\begin{tabular}{|c|c|c|c|c|c|c|c|c|c|c|}
\hline Parameters & \multicolumn{7}{|c|}{ Time interval in minutes } \\
\hline & BA & 5 & 10 & 15 & 20 & 25 & 30 & 35 & 40 \\
\hline HR(beat/min) & $80.1 \pm 2.22$ & $79.8 \pm 2.33$ & $79.5 \pm 2.42$ & $79.3 \pm 2.46$ & $78.2 \pm 2.47$ & $77.4 \pm 2.37$ & $74.2 \pm 2.1$ & $73.4 \pm 2.4$ & $72.5 \pm 2.5$ & $79.3 \pm 2.4$ \\
\hline RR(breath/min) & $23.7 \pm 0.73$ & $23.1 \pm 0.79$ & $18.6 \pm 0.82$ & $17.48 \pm 0.89$ & $17.43 \pm 0.94$ & $16.67 \pm 1.32$ & $15.74 \pm 1$. & $15.45 \pm 1$ & $15.03 \pm 1$ & $23.2 \pm 0.7$ \\
\hline RT(0c) & $37.81 \pm 0.77$ & $37.76 \pm 0.78$ & $37.68 \pm 0.81$ & $37.64 \pm 0.86$ & $37.45 \pm 0.88$ & $37.42 \pm 0.90$ & $37.4 \pm 0.9$ & $37.35 \pm 0.94$ & $37.29 \pm 0.96$ & $37.62 \pm 1.02$ \\
\hline
\end{tabular}

$\mathrm{BA}=$ Before anesthesia, $\mathrm{HR}=$ Heart rate, $\mathrm{RR}=$ Respiratory rate, $\mathrm{RT}=$ Rectal temperature

\begin{tabular}{|c|c|c|c|c|c|c|c|c|c|c|c|c|c|}
\hline \multirow[t]{2}{*}{ Parameter } & \multicolumn{13}{|c|}{ Time interval in minutes } \\
\hline & BA & 5 & 10 & 15 & 20 & 25 & 30 & 35 & 40 & 45 & 50 & 55 & 60 \\
\hline HR(beat/min) & $80.1 \pm 2.22$ & $79.7 \pm 2.23$ & $79.4 \pm 2.24$ & $79.3 \pm 2.35$ & $78.1 \pm 2.26$ & $77.3 \pm 2.28$ & $74.1 \pm 2.31$ & $73.3 \pm 2.35$ & $72.4 \pm 2.41$ & $72.2 \pm 2.47$ & $79.2 \pm 2.35$ & $79.4 \pm 2.24$ & $79.7 \pm 2.23$ \\
\hline $\begin{array}{l}\text { RR(breath/ } \\
\text { min) }\end{array}$ & $23.7 \pm 0.73$ & $23.4 \pm 0.78$ & $18.5 \pm 0.8$ & $17.4 \pm 0.88$ & $17.3 \pm 0.91$ & $16.6 \pm 1.12$ & $15.6 \pm 1.22$ & $15.4 \pm 1.3$ & $15.1 \pm 1.3$ & $19.3 \pm 0.77$ & $23.3 \pm 0.77$ & $235 \pm 0.64$ & $23.6 \pm 0.53$ \\
\hline $\mathrm{RT}(0 \mathrm{c})$ & $37.81 \pm 0.77$ & $37.676 \pm 0.78$ & $37.588 \pm 0.80$ & $37.54 \pm 0.85$ & $37.35 \pm 0.87$ & $37.32 \pm 0.89$ & $37.3 \pm 0.912$ & $37.25 \pm 0.93$ & $37.39 \pm 0.95$ & $37.282 \pm 1.02$ & $37.77 \pm 0.84$ & $37.78 \pm 0.79$ & $37.79 \pm 0.6$ \\
\hline
\end{tabular}

$\mathrm{BA}=$ Before anesthesia, $\mathrm{HR}=$ Heart rate, $\mathrm{RR}=$ Respiratory rate, $\mathrm{RT}=$ Rectal temperature 


\section{Diazepam-Ketamine and Acepromazine-Ketamine in Dogs of Local Breed in Mekelle, Ethiopia}

\begin{tabular}{|c|c|c|c|c|c|c|c|c|c|c|}
\hline \multicolumn{11}{|l|}{ Anesthetics } \\
\hline & & $\mathrm{HBC}$ & PCV & TEC & TLC & NTP & LYM & MN & EOS & BAS \\
\hline \multirow[t]{2}{*}{ Group 1} & Before anesthesia & $14.2 \pm 0.25$ & $42.2 \pm 0.25$ & $6.2 \pm 0.25$ & $10.2 \pm 0.25$ & $58.8 \pm 0.39$ & $29.8 \pm 0.53$ & $7.2 \pm 0.25$ & $3.4 \pm 0.27$ & $0.8 \pm 0.13$ \\
\hline & During anesthesia & $13.81 \pm 0.29$ & $41.62 \pm 0.29$ & $5.68 \pm 0.25$ & $9.19 \pm 0.33$ & $64 \pm 0.68$ & $27.1 \pm 0.67$ & $6.4 \pm 0.16$ & $2.5 \pm 0.16$ & $0.4 \pm 0.1632$ \\
\hline \multirow[t]{2}{*}{ Group 2} & Before anesthesia & $14.2 \pm 0.25$ & $42.2 \pm 0.25$ & $6.2 \pm 0.25$ & $10.2 \pm 0.25$ & $10.2 \pm 0.25$ & $29.8 \pm 0.53$ & $7.2 \pm 0.25$ & $3.4 \pm 0.27$ & $0.8 \pm 0.133$ \\
\hline & During anesthesia & $12.61 \pm 0.29$ & $40.59 \pm 0.27$ & $4.78 \pm 0.20$ & $7.78 \pm 0.19$ & $66.5 \pm 0.34$ & $26.1 \pm 0.38$ & $5.6 \pm 0.16$ & $2 \pm 0.21$ & $0.2 \pm 0.13$ \\
\hline \multirow[t]{2}{*}{ Group 3} & Before anesthesia & $14.2 \pm 0.25$ & $42.2 \pm 0.25$ & $6.2 \pm 0.25$ & $10.2 \pm 0.25$ & $10.2 \pm 0.25$ & $29.8 \pm 0.53$ & $7.2 \pm 0.25$ & $3.4 \pm 0.27$ & $0.8 \pm 0.13$ \\
\hline & During anesthesia & $12.63 \pm 0.29$ & $40.69 \pm 0.27$ & $4.76 \pm 0.20$ & $7.79 \pm 0.19$ & $66.58 \pm 0.34$ & $26.4 \pm 0.38$ & $5.7 \pm 0.16$ & $2.1 \pm 0.2108$ & $0.22 \pm 0.13$ \\
\hline
\end{tabular}

HBC = Hemoglobin concentration, PCV = Packed cell volume, TEC = Total erythrocyte count, TLC = Total leukocyte count, NTP = Neutrophil, LYM = Lymphocyte, $\mathrm{MN}=$ Monocyte, $\mathrm{EOS}=$ Eosinophil, BAS = Basophil

\section{Discussion}

Ketamine is rarely used alone because of its association with poor muscle relaxation, tachycardia and catalepsy or muscle rigidity and it is therefore commonly used in combination with xylazine, diazepam and acepromazine to minimize the untoward effects. In the present study, the onset of action, duration of action and recovery time after administration of xylazine and ketamine at $2 \mathrm{mg} / \mathrm{kg}$ and $10 \mathrm{mg} / \mathrm{kg}$, respectively were $6 \pm 2.12$, $91 \pm 6.28$ and $101.2 \pm 6.53$ minutes, respectively. The fastest onset of action was seen in dogs of group 1 . This might be due to rapid distribution of xylazine and ketamine combination into brain tissues. The highest duration of anesthesia was observed in the dogs of Group1. This might be due to wide-distribution of xylazine and ketamine combination in the body, because they are highly soluble in lipid and can be redistributed into muscles and adipose tissues [4]. The results obtained here were relatively in line with the findings of Sindak,et al.(2010) who found 8.3 minutes onset of action after administration of xylazine at dose rate of $1 \mathrm{mg} / \mathrm{kg}$ and ketamine at dose rate of $10 \mathrm{mg} / \mathrm{kg}$ body weight intramuscularly and Naqialbayati,(2015) who reported 96 minutes duration of action after administration of xylazine at dose rate of $1 \mathrm{mg} / \mathrm{kg}$ and ketamine at dose rate of $5 \mathrm{mg} / \mathrm{kg}$ body weight intramuscularly[24,27] .

In this study, the onset of action of xylazine and ketamine combination was relatively 6 minutes rapid when compared to the studies by Emami, et al.(2014) who found 12 minutes after administration of xylazine at dose rate of $1 \mathrm{mg} / \mathrm{kg}$ and ketamine at dose rate of $15 \mathrm{mg} / \mathrm{kg}$ body weight intramuscularly [11]. The duration of action of xylazine and ketamine combination was relatively 35.75 minutes longer when compared to the studies by Sindak, et al.(2010) reported 55.25 minutes[27]. The duration of action of xylazine and ketamine combination was relatively 19.4 minutes longer when compared to the studies by Emami, et al.(2010) found $71.60 \pm 3.07$ minutes [11]. The recovery time of xylazine and ketamine combination in the present finding was relatively 27.85 minutes longer when compared to the study by Sindak, et al.(2010) reported 73.15 minutes [27]. This finding difference in the present study from previous studies might be due to difference in breed and physiological status of the dogs or might be due to difference in dose of the anesthetic agents.
In this study, heart rate was decreased non- significantly at 30-45 minutes, respiratory rate was decreased non-significantly at 10-45 minutes and rectal temperature was decreased nonsignificantly at 20-45 minutes after administration of xylazine and ketamine combination

The decrease in heart rate, respiratory rate and rectal temperature in this study were in agreement with the studies by Sindak, et al.(2010) reported decreased heart rate at 3045 minutes after administration of xylazine and ketamine combination, decrease in respiratory rate and decrease in rectal temperature at 20-45 minutes after administration of xylazine and ketamine; Mwangi, et al.(2014) reported decreased rectal temperature at 30 minutes and Emami, et al.(2010) reported decreased respiratory rate at 5-55 minutes following administration of xylazine and ketamine combination. On the other hand, Afshar, et al.(2005) reported significant decrease in heart rate at 15-60 minutes after administration of xylazine and ketamine combination; Kul, et al.(2000) reported significant decreased in respiratory rate at 15 - 60 minutes after administration of xylazine and ketamine combination; Demirkan, et al.(2002) reported significantly remained lower respiratory rate than the baseline throughout the xylazine and ketamine anesthesia and rectal temperature remained significantly decreased at 30-60 minutes after administration of xylazine and ketamine combination $[1,9,11,19,23,27]$.

The decreases in rectal temperature after administration of xylazine and ketamine combination found in the present study were in contrary with the findings of Wyatt, et al.(2001) reported unchanged in rectal temperature after administration of xylazine at $1 \mathrm{mg} / \mathrm{kg}$ and ketamine at $10 \mathrm{mg} / \mathrm{kg}$ body weight intramuscularly in dogs [33].

The decrease in body temperature after the administration of the xylazine-ketamine, diazepam-ketamine and acepromazineketamine could be explained by blocking of the hypothalamic thermoregulatory center. The decrease in heart rate could be attributed to inhibition of the release of the neurotransmitter noradrenalin or depression of the sympathetic activity.

The decrease in respiratory rate could be attributed to depression of the respiratory center by the xylazine-ketamine, diazepam-ketamine and acepromazine-ketamine [30]. The non- 


\section{Breed in Mekelle, Ethiopia}

significant decrease in heart rate, respiratory rate and rectal temperature in the present study when compared to other studies might be due to difference in breed and physiological status of the dogs or might be due to difference in dose of the sedative agents.

In the present study, the average duration of anesthetic induction after administration of diazepam and ketamine at $0.1 \mathrm{mg} / \mathrm{kg}$ and $5 \mathrm{mg} / \mathrm{kg}$, respectively were $12 \pm 2.12$ and $37.8 \pm$ 1.92 minutes, respectively. This finding is in agreement with the studies by Ferreira, et al.(2015) reported 35.7 minutes of the average duration of anesthesia after administration of diazepam and ketamine combination, but the onset of action was slower in the present finding when compared to observations separated by Ferreira, et al.(2015) he had reported average 4.2 minutes after administration of diazepam and ketamine combination [13]. The slower onset of action in the present finding when compared to the other studies might be due to difference in breed of the dog or due to difference in physiological status of the dog.

In this study, heart rate was decreased non-significantly at 30-40 minutes, respiratory rate was decreased non-significantly at 10-40 and rectal temperature was decreased non-significantly at 20-40 minutes after administration of diazepam at $0.5 \mathrm{mg} /$ $\mathrm{kg}$ and ketamine at $10 \mathrm{mg} / \mathrm{kg}$ body weight intramuscularly. Relatively similar finding were reported by White, et al.(2001) who found decreased respiratory rate at the first 30 minutes after administration of the diazepam at $0.3 \mathrm{mg} / \mathrm{kg}$ and ketamine at 5 $\mathrm{mg} / \mathrm{kg}$ body weight intramuscularly on ten healthy dogs [31].

After administration of xylazine -ketamine, Diazepam ketamine and acepromazine - ketamine combinations the hemoglobin concentration, packed cell volume, total erythrocyte count, total leukocyte count, lymphocyte, monocyte, eosinophil and basophils were decreased non-significantly, but neutrophils were increased non-significantly.

Pooling of circulating blood cells in the spleen and other reservoirs secondary to decreased sympathetic activity could be the reason for a decrease in hemoglobin concentration, packed cell volume, total erythrocyte count, total leukocyte count, lymphocyte, monocyte, eosinophil and basophils [18]. The decrease in hemoglobin concentration, packed cell volume, total erythrocyte count, total leukocyte count, lymphocyte, monocyte, eosinophil and basophils after administration of the diazepam and ketamine combination might be attributed to the shifting of fluid from extra vascular compartment to intravascular compartment in order to maintain normal cardiac output in the dogs [29].

This finding is in agreement with the findings of Mahmud, et al.(2014) who had reported decreased the hemoglobin concentration, packed cell volume, total erythrocyte count, total leukocyte count, lymphocyte, monocyte, eosinophil and basophils and increased neutrophils after administration of diazepam at $0.4 \mathrm{mg} / \mathrm{kg}$ and ketamine at $10 \mathrm{mg} / \mathrm{kg}$ combination in dogs [20].

In the current study, heart rate was decreased nonsignificantly at 30-45 minutes, respiratory rate decreased non-significantly at 10-45 minutes after administration of the xylazine-ketamine, diazepam-ketamine and acepromazineketamine intramuscularly and rectal temperature decreased non-significantly at 20-45 minutes after administration of the xylazine-ketamine, diazepam-ketamine and acepromazineketamine combinations intramuscularly.

This finding is relatively similar with the findings of Amarpal, et al.(2010) who had reported decreased heart rate at 60 minutes after administration of the acepromazine and ketamine combination, decrease in respiratory rate at 10-60 minutes after administration of the acepromazine and ketamine combination and decrease in rectal temperature at 10-60 minutes intramuscularly after administration of the acepromazine and ketamine combination in dogs [2].

\section{Conclusion}

Ketamine is rarely used alone because of its association with poor muscle relaxation, visceral analgesia, tachycardia and catalepsy or muscle rigidity. Therefore, it is commonly used in combination with xylazine, diazepam and acepromazine to enhance muscle relaxation, to provide good visceral analgesia in case of abdominal surgery (including ovariohysterectomy) and thoracic surgery, to prevent seizures/convulsions and to prolong the duration of anesthetic effect. The study was conducted on 15 mature and apparently healthy local breed of dogs which were randomly grouped in to Group I, Group II and Group III. All dogs were premedicated using atropine $(0.04 \mathrm{mg} / \mathrm{kg} \mathrm{BW}$, S.C). After 15 mints premedication, anesthesia induced with xylazine-ketamine (1.0 mg $/ \mathrm{kg} / \mathrm{BW}+10.0 \mathrm{mg} / \mathrm{kg}$ BW, I.M) for Group I, diazepamketamine $(0.5 \mathrm{mg} / \mathrm{kg} / \mathrm{BW}+10.0 \mathrm{mg} / \mathrm{kg}$ BW, I.M) for Group II and acepromazine-ketamine $(0.05 \mathrm{mg} / \mathrm{kg} / \mathrm{BW}+10.0 \mathrm{mg} / \mathrm{kg} \mathrm{BW}$, I.M), were administered for G III. The anesthetic parameters; induction time, duration of anesthesia recovery period, the physiological parameters; temperature, heart rate, respiratory rate, and the hematological parameters; packed cell volume, total erythrocyte count, total leukocyte count, hemoglobin determination were recorded and analyzed in all three groups and all the anesthetic parameters were found statistically significant but the physiological and hematological parameters were statistically non-significant in all groups. The results of the present study concluded that xylazine-ketamine combination is useful anesthetic protocol for rapid induction, prolonged duration of anesthesia; diazepam-ketamine combination is useful anesthetic protocol for short duration of anesthesia and rapid recovery. All drug combinations do not affect the physiological and hematological parameters of the animals during the study time and all of them can be safe for surgical procedures if used safely and appropriately. However, further studies on several other anesthetic combinations i.e. (acepromazine + xylazine + ketamine and acepromazine + diazepam + ketamine) on local breed of dogs and several other anesthetic combinations may be conducted.

\section{Acknowledgements}

A special gratitude goes to Mekelle University, without its support; the study would not have been possible. A great thanks go to Dr. Yohannes, H. for all his help in analyzing the research 


\section{Breed in Mekelle, Ethiopia}

data and Mr. Yisehak, T. the surgery technician for his help and cooperation rendered during the experimental study. I never forget to say thanks to Mr. Kidane, W. the pathology laboratory staff worker for his help, patience, permission and full information during my working period.

\section{References}

1. Afshar S, Baniadam A, Marashipour P.Effect of xylazine -ketamine on arterial blood pressure, arterial blood $\mathrm{pH}$, blood gases, rectal temperature, heart rate and respiratory rate in goat. Bulletin of the Veterinary Institute in Pulawy.2005;49: 481-484.

2. Amarpal P, Kinjavdekar P, Aithal A, Pawde K, Singh J,Rahul U. Evaluation of Xylazine, Acepromazine and Medetomidine + Ketamine for general anesthesia in rabbits. Scandinavian Journal of Laboratory Animal Sciences.2017;37(3): 223-229.

3. Atalan H, Gunes V, Cihan M, Celebi F, Citil M.Comparisons of xylazine + ketamine- $\mathrm{HCl}$ anaesthetic agents with acepromazine + butorphanol + ketamine combinations for their clinical,cardiovascular and respiratory effects in dogs.2002;8:35-40.

4. Azizpour A, Hassani Y. Clinical evaluation of general anaesthesia with a combination of Ketamine HCL and Diazepam in pigeons. Journal of Agriculture. 2012;7(2):101-105. doi: 10.3923/ aj.2012.101.105

5. Bergamasco L, Osella C, Savarino P, Larosa G, Ozella L, Manassero $\mathrm{M}$, et al. Heart rate variability assessment in shelter dog. Application animal Science. 2010;125(1-2): 56-68.

6. Beteg F, Muste A, Mates N, Donisa A, Scurtu L, Bota A, et al. Observations concerning the effects of medetomidine on diazepamketamine induced anesthesia in dogs. Indian Journal of Veterinary Research. 2010; 43(10): 95-99.

7. Boutureira J, Trim C, Cornell K. Acute pulmonary edema after diazepam-ketamine in a dog. Journal of Veterinary Anesthesia and Analgesia.2007; 34(5): 371-376.

8. CSA. Central Statistical Agency: Report on monthly average retail prices of goods and services. Statistics Bulletn. 2008;416.

9. Demirkan G, Gokce I, Ozaydin D, Celebi F. Comparative study of butorphanol-ketamine and xylazine -ketamine combinations for their clinical, cardiovascular and respiratory effects in healthy dogs. Turkey journal of veterinary and animal science. 2002;26:10731079.

10. Durrani F, Ashraf M, Khan A. A comparison of the clinical effects associated with xylazine, ketamine and a xylazine-ketamine cocktail in pigeons (Columba Livia). Turkish Journal of Veterinary and Animal Science. 2009 ;33: 413-417.

11.Emami R, Sedighi R, Sarhaddi S. Cardiovascular and respiratory effects of romfidine or xylazine in ketamine anesthesia in dogs. Iranian journal of veterinary surgery. 2007;2(2):59-64.

12. Fayyaz S, Kerr C, Dyson H, Mirakhur K. The cardiovascular and pulmonary effects of anesthetic induction with isoflurane, diazepam-ketamine or diazepam-propofol in the hypovolemic dogs. Journal of Veterinary Anesthesia and Analgesia. 2009;36(2): 110123

13.Ferreira P, Dzikiti B, Zeiler E, Buck R, Nevill B, Gummow B. Anesthetic induction and recovery characteristics of a diazepam- ketamine combination compared with propofol in dogs, Journal of the South African Veterinary Association. 2015;86(1):1258.

14. Gaynor S, Muir W. Handbook of Veterinary Pain Management. Drugs acting on the central nervous system. 2nd edition. St. Louis: Mosby. 2008;78-109.

15.Gulanber E, Baştan A, Tasal I, Aktas M, Arikan N. Ketamine as general anesthesia. Journal of the faculty of veterinary medicine, Istanbul University. 2001;27(2):401-409.

16. Hazra S, De D, Roy B. Use of ketamine, xylazine, and diazepam anesthesia with retrobulbar block for phacoemulsification in dogs. Veterinary Ophthalmology. 2008;11(4): 255-259.

17. Junior E, Santos J, Russo C, Elsensaut P, Headley A. Evaluation of cortisol levels of dogs anesthetized with sevoflurane and premedicated with butorphanol. 2009;30(2): 425-433.

18. Kilic N. Physiological and hematological changes in ketamine and diazepam anesthesia in horse. Indian Journal of Veterinary. 2004;81:396-398.

19. Kul M, Koc Y, Alkand F, Ogurtan Z. The effects of xylazine-ketamine and diazepam-ketamine on arterial blood pressure and blood gases in dogs. Journal of Veterinary Research. 2000;4:123-132.

20. Mahmud A, Shaba P, Yisa H, Gana J, Ndagimba R, Ndagi S. Comparative efficacy of Diazepam, Ketamine and DiazepamKetamine combination for sedation or anesthesia. Journal of advances Veterinary Animal Research. 2014;1(3):107-113.

21. Mathews A. Pain assessment and general approach to management. Veterinary Clinical. North America Small Animal Practice. 2000;30(4): 729-755.

22. Muir W. Cylohexamine drug mixtures: The pharmacology of ketamine and ketamine combination drugs. Proceedings of second International Congress of Veterinary Anesthesia.Veterinary Publishing Co, Santa Barbara. 2008;4: 5-14.

23.Mwangi E, Mogoa M, Nguhiu J, Mulei M. Effects of epidural Ketamine, Xylazine and their combinations on body temperature in acepromazine-sedated dogs. International Journal of Advanced Research. 2014;2(4):336-340.

24. Naqialbayati T. A comparative study between of effect of tramadol and xylazine as premedication those followed by ketamine anesthesia in dogs. Kufa journal for veterinary medical sciences. $2015 ; 6: 2$

25. Orpet H, Welsh P. Handbook of Veterinary Nursing. Implementation a patient care plan. 1st edition, Black well Science Ltd., USA. 2002;10: 244-251.

26. Orskov T. Pain assessment in cats and dogs. Irish Journal of Veterinary science. 2010; 63(6): 362-364.

27. Sindak N, Camekerten I, Ceylan C. clinical evaluation of xylazineketamine anesthesia in bozova greyhounds. Journal of animal and veterinary advances. 2010;9(15): 2025-2029.

28.Tranquilli J, Thurmon C, Grimm A. Lumb and Jones' Veterinary Anesthesia and Analgesia. 4th edition. Oxford: Blackwell. 2007;80105

29. Wagner A, Muir W, Hinchclif K W. Cardiovascular effects of xylazine and detomidine in horse. American Journal of Veterinary Research. 1991; 52(5): 651-657. 
30.Walter H. Handbook of Veterinary Pharmacology: Drugs Acting on the Central Nervous System. Wiley-Blackwell. IOWA. 2008;81-107.

31. White K, Shelton K, Taylor P. Comparisons of diazepam-ketamine and thiopentone for induction of anaesthesia in healthy dogs. Journal of Veterinary Anaesthesia and Analgesia.2001; 28(1): 4248.
32.Winer J, Brown R, Michels K. Statistical principles in experimental designs. 3rd edition, Mcgraw hill series. 2001;1057.

33. Wyatt D, Scott W, Richardson E. The effects of prolonged ketaminexylazine intravenous infusion on arterial blood $\mathrm{pH}$, blood gases, mean arterial blood pressure, heart and respiratory rates, rectal temperature and reflexes in the rabbit. Journal of Veterinary Science. 1989;39(5):411-416. 